\title{
NGHIÊN CỨU MỐI LIÊN QUAN VÔI HÓA ĐộNG MẠCH CHỦ BỤNG VỚI THỜI GIAN MẮC BÊNH VÀ THỜI GIAN LỌC MÁU Ở BỆNH NHÂN BỆNH THẬ̀N MẠN TÍNH GIAI ĐOẠN CUỐI
}

\begin{abstract}
Vũ Thành $Đ$
TÓM TẮT

Mục tiêu: Nghiên cứu mối liên quan vôi hóa động mạch chủ bụng bằng chụp cắt lớp vi tính (CLVT) không tương phản với thời gian phát hiện bệnh thận mạn, thời gian lọc máu ở bệnh nhân bệnh thận mạn tính (BN BTM) giai đoạn cuối có và không có lọc máu. Phương pháp nghiến cứu: Nghiên cứu trên $89 \mathrm{BN}$ BTM giai đoạn cuối có chỉ định ghép thận tại Bệnh viện Quân y 103. Đánh giá vôi hóa động mạch chủ bựng trên hình ảnh CLVT không tương phản bằng chỉ số vôi hóa động mạch chủ bụng ACI (Abdominal Calcification Index). Phân tích tướng quan đơn biên và hồi quy Logistic đa biến giữa vôi hóa động mạch chủ bụng với thời gian mắc bênh thận mạn, thời gian lọc máu và một số yếu tố. Kết quả: Vôi hóa động mạch chủ bụng được quan sát thấy ở 67 bệnh nhân $(75,3 \%)$ (Median ACI: 4,82\%), trong đó, có 16 bênh nhấn có vôi hóa mức độ nặng ( $\mathrm{ACI} \geq 20 \%$ ). Tỷ lể bệnh nhân có vôi hóa động mạch chủ bụng tăng dẩn theo thời gian phát hiện bệnh thận và thời gian lọc máu trước ghép $(p<0,05)$. Phân tích hồi quy đa biến cho thấy vôi hóa động mạch chủ bunng liên quan có ý nghĩa với thời gian phát hiện bệnh thận trên 1 năm (OR: 9,975; $95 \%$ CI: $3,326-29,914)$ và̀ thời gian lọc máu trên 1 năm (OR: 7,179; 95\% CI: 1,551 - 33,238). Kết luận: Thời gian phát hiện bệnh thận mạn và thời gian lọc máu là yếu tố liên quan có ý nghĩa với sự xuất hiện vồi hóa động mạch chủ bụng ở bệnh nhân bệnh thận mạn giai đoạn cuối.
\end{abstract}

\section{SUMMARY}

ANALYZING THE ASSOCIATION BETWEEN ABDOMINAL AORTIC CALCIFICATION BY BY NON-CONTRAST COMPUTED TOMOGRAPHY SCAN WITH THE DETECTED-KIDNEY DISEASE DURATION, THE DIALYSIS DURATION IN ENDSTAGE RENAL DISEASE PATIENTS

Objectives: Analyzing the association between abdominal aortic calcification (AAC) by by non-contrast computed tomography (CT) scan with the detectedkidney disease duration, the dialysis duration in endstage renal disease (ESRD) patients with/without dialysis. Methods: A prospective study was conducted involving 89 ESRD patients who were candidated for kidney transplantation at 103 Military Hospital. Non-

\section{*Bệnh viện Quân y 103.}

**Họ viện Quân y.

Chịu trách nhiệm chính: Vũ Thành Đô

Email: dr.thanhdovu2318@gmail.com Ngày nhận bài: 10.9.2021

Ngày phản biện khoa học: 28.10.2021

Ngày duyệt bài: 12.11.2021 contrast CT scan was performed to determine the aortic calcification index (ACI) as a semi-quantitative measure of AAC. Analyzing the univariate correlation and the multivariable logistic regression between AAC and detected-kidney disease duration, dialysis pretransplant duration and some other factors. Results: There were 89 patients (68 males and 21 females), the median age was 36,0 years (Min-max: $18-66$ years). AAC was observed in 67 patients $(75,3 \%)$ (Median ACI: 4,82\%), in which, there were 16 patients had severe calcification (ACI $\geq 20 \%$ ). Prevalence of AAC significantly increased with age, BMI, detectedkidney disease duration and dialysis pre-transplant duration $(p<0,05)$. AAC was significantly associated with age older than 30 (OR: 21,33; 25\% CI: 5,116 $88,96)$, detected-kidney disease duration (OR: 9,975; 95\% CI: 3,326 - 29,914) and/or dialysis pre-transplant duration more than 1 year (OR: 7,179; 95\% CI: 1,551 33,238). Conclusions: Detected-kidney disease duration and dialysis duration are significantly associated with the occurrence of AAC in ESRD patients.

Keywords: Abdominal aortic calcification, endstage renal disease, risk factors of AAC.

\section{I. ĐẶT VẤN ĐỀ}

Bệnh lý tim mạch là nguyên nhân gây tử vong phổ biến nhất ở những BN BTM, kể cả có hay không điều trị thận nhân tạo. Nguy cơ biến cố tim mạch cao ở nhóm BN này có sự tham gia của quá trình vôi hóa mạch máu [1]. Vôi hóa mạch máu và xơ cứng động mạch được xác định là các yếu tố dự báo độc lập về tử vong do mọi nguyên nhân và tử vong do tim mạch ở BN ESRD [2]. Có nhiêu phương pháp để xác định vôi hóa mạch máu, trong đó, chụp CLVT không tương phản có thể phát hiện và lượng giá các tổn thương vôi hóa mạch máu.

Hiện nay, kết quả của nhiều nghiên cứu trên thế giới đã cung cấp bằng chứng về mối liên quan của một số yếu tố nguy cơ với quá trình vôi hóa mạch máu nói chung, và trên đối tượng $B N$ BTM nói riêng. Tuy nhiên, tại Việt Nam, vấn đề này chưa được nghiên cứu nhiểu và đánh giá đầy đủ. Vì vậy, chúng tôi thực hiện nghiên cứu với mục tiêu: Tim hiếu mối liên quan giữa đặc điểm vôi hóa động mạch chủ bụng trên chụp cắt lớp vi tính 16 dãy ở bệnh nhân bệnh thận mạn tính giai đoạn cuối với một số yếu tố nguy cớ.

II. ĐỐI TƯỢNG VÀ PHƯƠNG PHÁP NGHIÊN CỨU

89 BN BTM giai đoạn 5 có chỉ định ghép thận tại Bệnh viện Quân y 103, Học viện Quân y từ 
tháng 9/2020 đến tháng 6/2021.

Đánh giá AAC trên phim CLVT ổ bụng không có thuốc cản quang, các lát cắt với độ dày 5 $\mathrm{mm}$. Tổn thương AAC được xác định khi có một vùng $\geq 1 \mathrm{~mm}^{2}$ có hiển thị mật độ $\geq 130$ đơn vị Hounsfield $(\mathrm{HU})$ nằm trên thành động mạch.

Điểm ACI được tính cho đoạn động mạch chủ bụng kéo dài từ động mạch thận đển phân nhánh động mạch chậu chung. Các mặt cắt ngang của động mạch chủ bụng trên mỗi lát cắt được chia thành 12 phần bằng nhau, vôi hóa xuất hiện ở mỗi phần được tính là 1 điểm, điểm ACI cho mỗi lát cắt động mạch chủ bụng từ 0 đến 12 điểm. Tổng điểm ACI\% của đoạn động mạch chủ bụng được tính bằng tổng điểm $\mathrm{ACI}$ của tất cả lát cắt chia cho tích số lát cắt $(\mathrm{n})$ và 12 [3].

Phân tích mối tương quan giữa $A A C$ và một số yếu tố nguy cơ tiềm năng: Giới tính; tuổi; BMI; thời gian phát hiện BTM; phương pháp điều trị trước ghép; thời gian lọc máu...

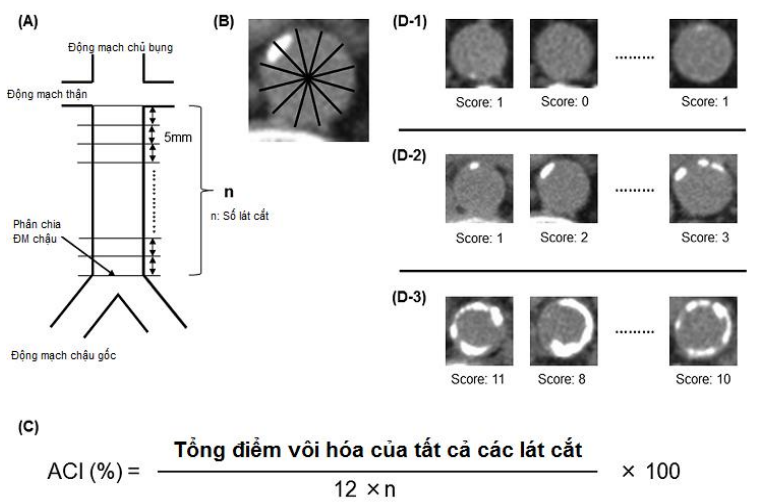

Hình 2.1. Chỉ số vôi hóa động mạch chủ bung ACI\%

*Nguồn: Theo Tatami và cs (2015) [3]

III. KẾT QUẢ NGHIÊN CỨU VÀ BÀN LUÂ̂N

3.1. Đặc điểm tổn thương vôi hóa động mạch chủ bụng trên hình ảnh chụp CLVT

Bảng 3.1. Đặc điểm chung bệnh nhân nghiên cứu ( $n=89)$

\begin{tabular}{|c|c|}
\hline Đặc điểm bệnh nhân & $\begin{array}{c}\text { Mean } \mathbf{~} \\
\text { SD/Median (Min- } \\
\text { max)/n (\%) }\end{array}$ \\
\hline Giới tính nam & $68(76,4)$ \\
\hline Tuối (Năm) & $36,0(18-66)$ \\
\hline BMI (Kg/m²) & $20,71 \pm 2,71$ \\
\hline Thời gian phát hiện & $36,0(1-266)$ \\
\hline
\end{tabular}

\begin{tabular}{|c|c|}
\hline bệnh thận (Tháng) & $70(78,7)$ \\
\hline Có lọc máu trước ghép & 70 \\
\hline $\begin{array}{c}\text { Thời gian lọc máu trước } \\
\text { ghép (Tháng) }\end{array}$ & $6,0(0-98)$ \\
\hline
\end{tabular}

BMI: Body mass index.

Mean: Giá trị trung bình. SD: Độ lệch chuẩn. Median: Trung vị. n: Số bệnh nhân.

Bảng 3.2. Đặc điểm vôi hóa động mạch chủ bụng trên hình ảnh CLVT

\begin{tabular}{|c|c|}
\hline Tổn thương & $\begin{array}{c}\text { Bệnh nhân nghiên } \\
\text { cứu }(\mathbf{n}=\mathbf{8 9})\end{array}$ \\
\hline Không có vôi hóa, $\mathrm{n}(\%)$ & $22(24,7)$ \\
\hline Có vôi hóa, $\mathrm{n}(\%)$ & $67(75,3)$ \\
\hline$-\mathrm{ACI}<20, \mathrm{n}(\%)$ & $51(76,1)$ \\
\hline$-\mathrm{ACI} \geq 20, \mathrm{n}(\%)$ & $16(23,9)$ \\
\hline ACI trung bình & \\
\hline - Mean \pm SD & $8,59 \pm 10,92$ \\
\hline - Median (Min - Max) & $4,82(0-42,13)$ \\
\hline
\end{tabular}

ACI: Abdominal Calcification Index.

Mean: Giá trị trung bình. SD: Độ lệch chuẩn. Median: Trung vị. n: Số bệnh nhân.

Trong các phương pháp khả thi để phát hiện tổn thương vôi hóa mạch máu, chúng tôi lựa chọn chụp CLVT ổ bụng không tương phản, là kỹ thuật được chỉ định thường quy và được $\mathrm{BHYT}$ chi trả $100 \%$ ở BN tuyển chọn ghép thận. Bằng phương pháp này, chúng tôi ghi nhận tỷ lệ $\mathrm{BN}$ có AAC (ACI > 0) chiếm 75,3\%, trong đó, có 16 bệnh nhân có vôi hóa mức độ nặng ( $A C I \geq 20 \%)$ (Bảng 3.2). Điểm $\mathrm{ACI}$ nhỏ nhất là $0 \%$, lớn nhất là $42,13 \%$, median: $4,82 \%$.

3.2. Liên quan giữa vôi hóa động mạch chủ bụng với thời gian phát hiện bệnh thận mạn, thời gian lọc máu và một số thông số

Tuổi là yếu tổ nguy cơ tim mạch và mach máu truyền thống. Tỷ lệ $A A C$ khác nhau có ý nghĩa thống kê giữa các nhóm tuổi $(p<0,0001)$. Chúng tôi nhận thấy có tương quan tương đối chă̆t chẽ $(r=0,605, p<0,0001)$ giữa $A A C$ và tuổi BN (Bảng 3.3), tuổi từ 30 trở lên được chứng minh là yếu tố nguy cơ của $A A C$ (OR: 21,33; 95\% CI: 5,116 - 88,96) (Bảng 3.4). K. Furusawa [5] cũng ghi nhận kết quả tương tự. H. Verma và cộng sự (20019) còn ghi nhận tuổi trung bình của BN có vôi hóa mức độ nặng $(\mathrm{ACI}$ $\geq 20 \%$ ) cao hơn có ý nghĩa thống kề so với nhóm vôi hóa mức độ nhe (ACI $<20 \%)$ ( $p=$ $0,0013)$ [4]. Đặc biệt, $A A C$ còn xuất hiện ở những BN trẻ tuổi (<30 tuổi).

Bảng 3.3. Môi tương quan đớn biến giữa chỉ số ACI và một số chỉ số

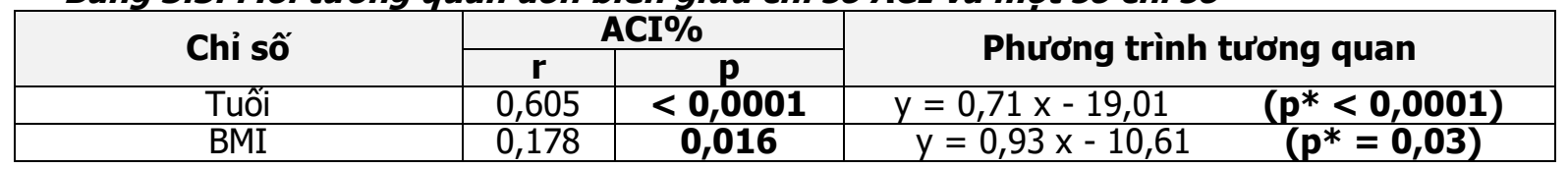




\begin{tabular}{c|c|c|ccc}
\hline Thời gian phát hiện & 0,369 & $<\mathbf{0 , 0 0 0 1}$ & $y=0,07 x+4,99$ & $\left(\mathbf{p}^{*}=\mathbf{0 , 0 0 1}\right)$ \\
\hline Thời gian lọc máu & 0,162 & $\mathbf{0 , 0 3 3}$ & $y=0,13 x+6,59$ & $\left(\mathbf{p}^{*}=\mathbf{0 , 0 0 9}\right)$
\end{tabular}

r: Hệ số tương quan. p: Kendall's tau-b Test. p*: ANOVA.

$A A C$ xuất hiện nhiều nhất ở nhóm $B N$ có thể trạng trung bình và thừa cân (Lần lượt là 55,2 và $22,4 \%)$, trong đó, đa số BN thừa cân đều có vôi hóa động mạch $(15 / 18,83,3 \%)$. Vôi hóa mức độ nặng ở nhóm thừa cân cũng có tỷ lệ cao nhất $(43,8 \%)$, gợi ý rẳng những BN có BMI cao có nguy cơ AAC cao hơn $(r=0,178, p=0,016)$ (Bảng 3.3). Ter Braake A.D. và cộng sự [6] cũng ghi nhận sự khác nhau về BMI trung bình giữa 2 nhóm có/không có $\mathrm{AAC}(\mathrm{p}<0,001)$.

Bảng 3.4. Hồi quy Logistic vôi hóa động mạch chủ bụng với một số yếu tố nguy cơ tiềm năng

\begin{tabular}{|c|c|c|c|}
\hline Yếu tố & OR & Khoảng tin cậy 95\% & $\mathbf{p}$ \\
\hline Giới nam & 1,767 & $0,604-5,167$ & 0,295 \\
\hline Tuối $\geq 30$ & $\mathbf{2 1 , 3 3}$ & $5,116-88,96$ & $<\mathbf{0 , 0 0 0 1}$ \\
\hline BMI $\geq 23$ & 1,827 & $0,475-7,021$ & 0,543 \\
\hline Thời gian phát hiện bệnh thận $\geq 1$ năm & $\mathbf{9 , 9 7 5}$ & $3,326-29,914$ & $<\mathbf{0 , 0 0 0 1}$ \\
\hline Có lọc máu & 0,294 & $0,062-1,392$ & 0,139 \\
\hline Thời gian lọc máu $\geq 1$ năm & $\mathbf{7 , 1 7 9}$ & $1,551-33,238$ & $\mathbf{0 , 0 0 5}$ \\
\hline
\end{tabular}

OR: Tỷ suất chênh. p: Pearson Chi - Square Test.

Thời gian phát hiện bênh thân là phản ánh tương đối của thời gian tiến triển bệnh, cũng là thời gian xuất hiện của các rối loạn gây ra bởi BTM. Hiểu theo nghĩa rộng, thời gian phát hiện bệnh thận càng dài sẽ làm tăng nguy cơ $A A C$. Chúng tôi nhận thấy tỷ lệ $A A C$ gặp nhiêu nhất ở nhóm $B N$ phát hiện bệnh thận trên 5 năm $(32,8 \%)$, thấp nhất ở nhóm phát hiện bệnh thận dưới 1 năm $(14,9 \%)$. Sư khác nhau giữa các nhóm có ý nghĩa thống kề $(p<0,0001)$. Hai yếu tố này có tương quan thuân khá chặt chẽ ( $r=$ $0,369, p<0,0001$ ) (Bảng 3.3). Những $B N$ có thời gian phát hiện bệnh thận trên 1 năm có nguy cơ AAC cao hơn 9,975 lần so với nhóm phát hiện bênh dưới 1 năm (Bảng 3.4). Tuy nhiên, khi phân tích liên quan giữa mức độ nặng của vôi hóa và thời gian phát hiện bệnh thận, sự khác nhau chưa có ý nghĩa thống kê ( $p>0,05)$.

Goldsmith D.J. và cộng sự nghiên cứu trên $B N$ thận nhân tạo chu kỳ có theo dõi dọc (10-25 năm), kết quả cho thấy vôi hóa mạch máu có tỷ lệ $39 \%$ đối với những $B N$ bắt đâu lọc máu, và $92 \%$ với những BN loc máu trung bình 16 năm. Mức độ nặng của vôi hóa cũng tăng lên cùng với thời gian loc máu [7]. Kết quả này tương đồng với kết quả trong nghiên cứu của chúng tôi, nhóm $B N$ có thời gian lọc máu trên 1 năm có tỷ lệ AAC cao hơn so với lọc máu dưới 1 năm (56 so với 44\%, $p=$ $0,005)$. Tỷ lệ vôi hóa mức độ nặng cũng khác nhau có ý nghĩa thống kê khi so sánh với thời gian lọc máu $(p=0,009)$. Thời gian lọc máu trên 1 năm được chứng minh là yếu tố nguy cơ của $A A C$ (Bảng 3.4), thời gian lọc máu càng dài, điểm ACI càng cao $(r=0,162, p=0,033)$ (Bảng 3.3).

\section{KẾT LUÂ̂N}

Thời gian phát hiện bệnh thận mạn tính và thời gian lọc máu là yếu tố gia tằng nguy cơ vôi hóa động mạch chủ bụng ở bệnh nhân bệnh thận mạn tính giai đoạn cuối.

\section{TÀI LIÊU THAM KHẢO}

1. Jankowski J., Floege J., Fliser D., et al. (2021), "Cardiovascular Disease in Chronic Kidney Disease: Pathophysiological Insights and Therapeutic Options", Circulation, 143(11), 1157-1172.

2. Timofte D., Dragos D., Balcangiu-Stroescu A. E., et al. (2020), "Abdominal aortic calcification in predialysis patients: Contribution of traditional and uremia-related risk factors", Experimental And Therapeutic Medicine, 20(1), 97-102.

3. Tatami Y., Yasuda Y., Suzuki S., et al. (2015), "Impact of abdominal aortic calcification on long-term cardiovascular outcomes in patients with chronic kidney disease", Atherosclerosis, 243(2), 349-355.

4. Verma H., Sunder S., Sharma B., et al. (2021), "Prevalence of Vascular Calcification in Chronic Kidney Disease Stage 4 and 5 Patients and its Correlation with Inflammatory Markers of Atherosclerosis", Journal of Kidney Diseases Transplantation, 32(1), 30.

5. Furusawa K., Takeshita K., Suzuki S., et al. (2019), "Assessment of abdominal aortic calcification by computed tomography for prediction of latent left ventricular stiffness and future cardiovascular risk in pre-dialysis patients with chronic kidney disease: A single center crosssectional study", International journal of medical sciences, 16(7), 939.

6. Ter Braake A. D., Govers L. P., Peeters M. J., et al. (2021), "Low plasma magnesium concentration and future abdominal aortic calcifications in moderate chronic kidney disease", BMC Nephrology, 22(1), 1-10.

7. Goldsmith D. J., Covic A., Sambrook P. A., et al. (1997), "Vascular calcification in long-term haemodialysis patients in a single unit: A retrospective analysis", Nephron, 77(1), 37-43. 